was founded at Salem in the year I867, by the munificence of George Peabody, with the design of promoting the study of science in his native county of Essex. The first Annual Report of the Trustees of this Academy, made in January, 1869, shows that it is already fully organized, with an able corps of officers and a well-ordered museum, library, \&c., and the activity of its Director and Curators is evident not only in the extent and fine condition of the collections, but in the zeal and ability with which the various publications of the Academy are conducted. Advantage was taken of the present occasion to make the formal transfer of the building of the Museum to the Trustees, and its delivery and acceptance by the Director, Mr. F. W. Putnam. In an eloquent address the President of the Academy, Mr. William C. Endicott, gave the history of the Museum from its foundation, in I80I, as the East India Marine Hall, to its purchase and reorganization in its present form. The Essex Institute, which is well known by its Proceedings, Bulletin, and Historical Collections, is now incorporated with the Peabody Academy of Science.

The address of Dr. B. A. Gould, the retiring President of the Association, dealt with the Position of Men of Science in America.

Everything which a hearty good will and an intelligent appreciation of science could do was done to promote the happiness and forward the plans of the Association and its members, alike by the city authorities of Salem, the various scientific bodies, and private individuals. We confess we should have been glad to learn that our English scientific men had been represented at the meeting, as America was represented at Exeter by Professors Newton and Lynan.

The Association will meet next year at Troy, New York, under the presidency of Professor Chauvenet, of St. Louis University.

The following, which were among the papers read at the meeting, will give an idea, not only of the great scientific importance of the congress, but of the direction in which many of the most eminent scientific men in America are working at the present time:-

SeCtion A. Mathematics, Physics, and Chemistry.-On the Total Eclipse of Ang. I869; B. Pierce.-On Quintuple Algebra; B. Pierce.-Determination of the Mechanical Equivalent of Heat, by means of the modern ice and cooling machines; P. H. Van der Weyde. - The Spectral Bands considered as harmonics of one or more fundamental longer waves, lying beyond in the invisible caloric rays; P. H. Van der Weyde.-On the andible transmission of musical melodies by means of the Electric Telegraph ; P. H. Van der Weyde.-Electricity not a self-existent fluid, but a mode of motion of matter; P. H. Van der Weyde.Flame Temperatures, in their relations to compositions and Iuminosity; B. Silliman and $H$. Wurtz. - On the relation between the Intensity of Light produced by the Combustion of Illuminating Gas and the Volume of Gas consumed; B. Silliman. -Causes of the Failure of Lightning Rods ; J. Bushee.-Conditions of a perfect Lightning Rod; J. Bushee.-The Laws of the Deflection of Beams tested by experiment; W. A. Norton.The physical theory of the Principle of the Lever; W. A. Norton. - Planetary Influence on Rainfall and Temperature; P. E. Chase. - The use of the Thermometer to determine the period of Solar Rotation; P. E. Chase--Some observations on the Solar Eclipse at Montreal, by Dr. C. Smallwood, with Photographs taken by Wm. Notman. Communicated by B. Edwards.-A new method of observing Contacts at a Solar Eclipse by the Spectroscope ; C. A. Young. - The Spectrum of the Solar Prominences and Corona, as observed at Burlington, Iowa, in the last Solar Eclipse, and the coincidence between the bright lines of Corona Spectrum and those of the Spectrum of the Aurora Borealis ; C. A. Young.-The Solar Eclipse, and the Outlines of the Corona as observed at Des Moins; T. Bassnett. - Remarkable case of freezing Fresh-water Pipes in Salt-water; W. W. Wheilden. --The Thermodynamics of Waterfalls; A. M. Mayer.-On some further evidence of the existence of a System of Arctic Winds; J. H. Coffin. - The present condition of Lighthouse Illumination in the United States; J. Henry. - A new method of rendering the Needle of a Galvanometer definitely astatic; M. G, Farmer.-On an improved construction of the Holtz Electrical Machine, adajted for the analysis of the phenomena of this variety of machine, and for Class-room use; R. E. Rogers.

SeCtion B. Gcology and Natural History.-Comparison of the Coral Fauma of the Atlantic and Pacific Coasts of the Isthmus of Darien, as bearing on the supposed former connection between the two Oceans; A. E. Verrill.-On certain Peculiarities in the distribution of Marine Life on the Sea-bottom of the Bay of Fundy ; A. E. Verrill.-American Phyllopod Crus. tacea; A. E. Verrill. - The Homologies and general structural relations of the Polyzoa; A. Hyatt.-Observations on a new genus of Polyzoa; A. Hyatt.-New Species of Fishes obtained by Prof. Orton in the valleys of the Maranon and Napo; T. Gill. - Notice of some new Fossil Plants, from Gaspé, discovered by Prof. J. W. Dawson; J. S. Newberry. -On some points in the Geology of North Carolina; W. C. Kerr.-Preliminary notice of the Lamellibranchiates of the Upper Helderberg, Hamilton and Chemung Groups: J. Hall. - On the Classification of the Diurnal Lepidoptera; S. H. Scudder.-The Morphology of the Abdominal Appendages of Butterflies; $S$. H. Scudder, - The value of the characters drawn from the external Armature of Lepidopterous Larvæ; S. H. Scudder. A classification of the Eggs of Butterfies; S. H. Scudder. - Two new genera of Extinct Cetacea; E. D.' Cope.-Discovery of the Ammonoosuc Gold Field; H. Wurtz. - Note upon the Palæotrochis; $\mathrm{H}$. Wurtz. - Notices of some new Tertiary and Cretaceous Fishes; O. C. Marsh.-Metamorphosis of Siredon into Amblystoma ; O. C. Marsh.-On some new Mosasauroid Reptiles from the Greensand of New Jersey ; O. C. Marsh.-Homologies of the Palrechinida; Alex. E. R. Agassiz.-On Surface Changes in Maine indicating the length of time since the close of the Quarternary Period; N. T. True-Compression as an agent in Geological Metamorphism, with illustrations of distorted pebbles in conglomerates; G. L. Vose. - On the Plasticity of Pebbles and Rocks; W. P. Blake.-Flora and Famna of the Freshwater Tertiaries of Oregon and Idaho; J. S. Newberry.-On new species of Fishes obtained by Prof. Orton in the Valleys of the Maranon and Napo; T. Gill.

Sub-Section C. Archeology and Ethnology.-Conjectural explanation of Uses of the Embankments of the Moind Builders; L. H. Morgan. - Discovery of the Remains of the Horse among the Ancient Ruins of Central America; O. C. Marsh.-Exhibition of a few interesting Implements collected by $R$. W. Haskins from Indian Graves on the banks of the Ohio, with special reference to the boring of holes in stone implements; F. W. Putnam.

\section{NEW STAR-ATLAS}

Mr. R. A. Proctor has planned a star-atlas on a plan which presents several advantages. The celestial sphere is to be divided according to this plan into twelve equal parts, each pentagonal in shape; but, each map being made circular, there is a slight overlapping, which prevents any star-group from being broken off at the edge of a map, as in all the arrangements hitherto adopted. Owing to the equality of the maps and the choice of a central projection (the equidistant) the distortion is reduced to a minimum. In fact, for the first time in the history of star-mapping, a plan is adopted by which, with a moderate number of maps, there is no appreciable distortion or scale-variation. The woodcut which gives (on a reduced scale and with inverted colours) a portion of Map 2 of the series (where it overlaps Map 4), exhibits some of the principal peculiarities of the new scheme. It will be noticed that though this portion belongs to the outer portion of the map (where the distortion is greatest) the figures between the parallels and meridians are of their proper shape. The arrow indicating precession in direction and magnitude (for 100 years) is a novel and very simple mode of exhibiting this important relation. The way in which the constellation-names are introduced is also new, and seems preferable to the old arrangement, in which the name straggling over the whole constellation at once confused the star-grouping, and was itself almost illegible unless printed in very large letters. The figure also includes instances of the mode of 
marking double, triple, and multiple stars, binaries (known or suspected), variables, Messier's nebulæ, Sir W. Herschel's classification of his nebulæ, and so on.

All stars in the B.A. Catalogue down to the sixth magnitude inclusive are to be introduced, besides all the objects in the Bedford Catalogue, Messier's nebulæ, about 100 variables, red stars, and other objects of interest (in all about I,500 objects). The scale of the maps is to be that of a 20 -inch globe, and each map will be rather more than thirteen inches in diameter.

Mr. Proctor's series of gnomonic maps, in which the sphere is divided into the same set of pentagons, which

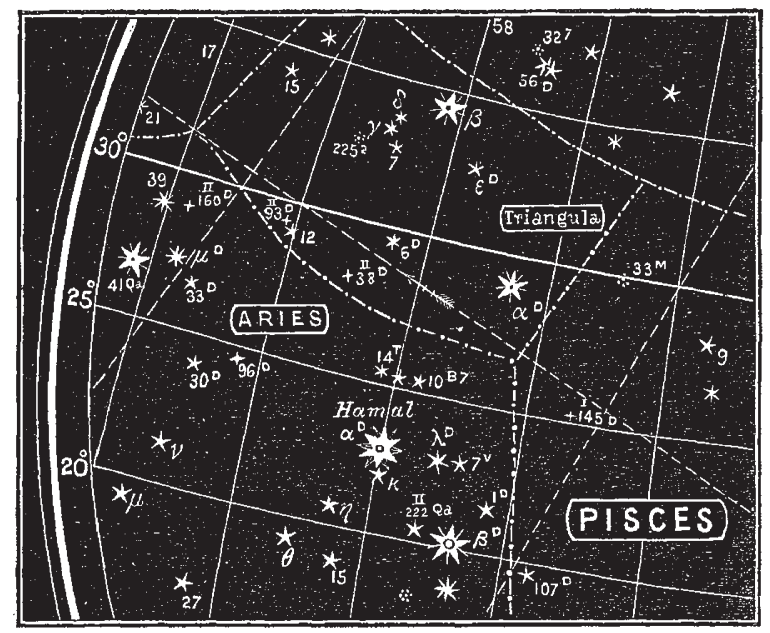

are arranged into two sets of six (namely, five northern equatorial maps around the north polar map, and five southern pentagons similarly arranged around the south polar map) will be added as index maps. As in these maps the constellation figures (coloured) are introduced, all necessity of adding these figures to the large maps is avoided, and so the clearness of the maps is much increased.

A letter-press introduction, with a list of star-names, will add to the completeness of the maps. Mr. Brothers, of Manchester, will photo-lithograph the maps if it should appear from the receipt (by him) of a sufficient number of names as subscribers, that the scheme is approved of by astronomers. He will supply to subscribers a specimen of Map 2, which alone is yet completed.

\section{LETTERS TO THE EDITOR}

[The Editor does not hold himself responsible for opinions expressed" by his Correspondents.]

Personal Equation of Astronomical Observers

CAN any of your readers inform me whether an attempt has hitherto been made to determine the absolute Personal Equation of Astronomical Observers? The most important of all astronomical observations consists in noting the time of passage of a star across the wires of a transit instrument; but it is found that no two observers exactly agree in the time assigned to the passage. From peculiar habit or bodily constitution some observers almost invariably register the passage of a star a fraction of a second before other observers. From the Introduction to the volumes of Greenwich Observations, we learn that it is the practice at the national Observatory to compare the observations of the junior observers with those of the principal observer, and to assume that the latter is correct. All the observations are th us brought into consistency with each other; but it is not known, I believe, whether all the time observations may not be a fraction of a second too soon or too late.

Camnot this question be determined experimentally in a very simple manner? Imagine an artificial star, formed by a minute electric spark, placed at a considerable distance, say three miles, and made to move across the field of a transit instrument at a rate not very different from the average "apparent rate of stars observed (say nine inches per second): very simple mechanism might be devised to register upon the chronograph of the observatory the exact moment at which the star is absolutely upon each of the cross wires of the telescope. At the same time the observer, whose error is to be determined, should endeavour to record in the ordinary way the passage of the star, and the difference of time, as shown on the chronograph, would give the required error. Every observer might thus be put through a kind of exercise, which would inevitably show the degree of his proficiency, or detect any change in his habits of observation.

I need hardly say, that however small may be the remaining personal error unallowed for in the Greenwich observations, the time may come when the determination of some most important astronomical question may depend upon that quantity. And though those observations may at any one time be rendered perfectly consistent inter se, by reference to one observer's result, yet they cannot be strictly comparable with the observations of other observatories, or those of the same observatory at distant periods of time, because the one same observer would not be present to give the assumed standard. It might be of considerable importance, therefore, to establish a mechanical criterion of the accuracy of time observations which could be appealed to at any observatory, and at any future time. I have not been able to learn that such an experiment has hitherto been tried.

\section{J.}

The Fertilisation - of Winter flowering Plants

WidL you permit me to add a few words to Mr. Bennett's letter, published at p. 58 of your last number? I did not cover up the Lamium with a bell-glass, but with what is called by ladies, "net." During the last twenty years I have followed this plan, and have fertilised thousands of flowers thus covered up, but have never perceived that their fertility was in the least injured. I make this statement in case anyone should be induced to use a bell-glass, which I believe to be injurious from the moisture of the contained air. Nevertheless, I have occasionally placed flowers, which grew high up, within small wide-mouthed bottles, and have obtained good seed from them. With respect to the Vinca, I suppose that Mr. Bennett intended to express that pollen had actually fallen, without the aid of insects, on the stigmatic surface, and had emitted tubes. As far as the mere opening of the anthers in the bud is concerned, I feel convinced from repeated observations that this is a most fallacious indication of self-fertilisation. As Mr. Bennett asks about the fertilisation of Grasses, I may add that Signor Delpino, of Florence, will soon publish some novel and very curious observations on this subject, of which he has given me an account in a letter, and which I am glad to say are far from being opposed to the very general law that distinct individual plants must be occasionally crossed.

Down, Beckenham, Kent, Nov. I3

Charles Darwin

\section{Elimination of Alcohol}

AtLow me to remark on a statement made in one of the chemical notes of last week's NATURE

A new test for alcohol discovered by M. Lieben is there de. scribed, and its alleged value in solving an important physiolo. gical problem is dwelt upon. Now the real course of events has been as follows :-Since the year 1860, when MM. Lallemand, Duroy, and Perrin published their researches on alcohol and anæsthetics, the old belief in the combustion of alcohol within the organism has been almost entirely upset; and it was supposed that this substance was entirely eliminated without change. Dr. Anstie was, I believe, the first who publicly criticised the conclusions of these physiologists, and showed, by a number of experiments, that a small proportion only of the alcohol introduced is excreted by the kidneys. [See Dr. Anstie, "Stimulants and Narcotics," Macmillan, 1864 ; also further researches recorded in his Lectures on Acute Diseases at the College of Physicians, Lancet, 1867, vol. ii.]

The question was next taken up by Dr. Thudichum, who estimated the amount of alcohol excreted by a number of men after they had taken a considerable quantity of wine, and proved it to be only one-half per cent. of the total amount swallowed. Finally, the writer of this, during 1866 and 1867 , made numerous experiments in the same direction. In these, not only was it shown that alcohol can be detected in the urine secreted during 